\title{
Evaluation of Reid's Combined Colposcopic Index as a predictor of cervical intraepithelial lesion
}

\author{
Indu Verma ${ }^{1 *}$, Pratibha Pundhir', Tejinder Kaur², Veena Jain ${ }^{2}$, Dinesh $\operatorname{Sood}^{3}$
}

\begin{abstract}
${ }^{1}$ Department of Obstetrics and Gynaecology, Maharishi Markandeshwar Institute of Medical Sciences and Research, Mullana, Ambala, Haryana, India

${ }^{2}$ Department of Oncology and Obstetrics and Gynaecology, MDOH, Ludhiana, Punjab, India

${ }^{3}$ Department of Anaesthesiology, DMC and H, Ludhiana, Punjab, India
\end{abstract}

Received: 02 July 2018

Accepted: 27 July 2018

\section{*Correspondence:}

Dr. Indu Verma,

E-mail: drdineshsood@gmail.com

Copyright: (c) the author(s), publisher and licensee Medip Academy. This is an open-access article distributed under the terms of the Creative Commons Attribution Non-Commercial License, which permits unrestricted non-commercial use, distribution, and reproduction in any medium, provided the original work is properly cited.

\section{ABSTRACT}

Background: Carcinoma cervix is the commonest cancer among women worldwide and in India it accounts for $80 \%$ of all genital cancers. Screening methods include cervical cytology, human papilloma virus testing and colposcopy. Objective of present study was to evaluate suspicious cervix colposcopically using Reids Colposcopic Index (RCI) and to correlate RCI with histopathological findings.

Methods: This was a prospective cross sectional study done on 125 women with clinical diagnosis of suspicious cervix. Colposcopy was performed and grading of the disease was done according to RCI. Positive cases were subjected to cervical biopsy and endocervical curettage was performed in unsatisfactory colposcopy.

Results: Colposcopy was done on 125 women with suspicious cervix. Out of 125, sixty two showed abnormal colposcopic findings which were graded according to RCI into Low grade disease predicting histological diagnosis of CIN1 in 47, Intermediate grade disease predicting histological diagnosis of CIN $1 / 2$ in 11 and High grade disease predicting histological diagnosis of CIN2/3 in 4 women. Colposcopy of one women suggested invasive carcinoma and was confirmed on histopathology to be microinvasive squamous cell carcinoma. Six women with unsatisfactory colposcopy showed benign histopathology. Sensitivity, specificity, predictive value and false negative rate of colposcopy for invasive disease was $50 \%, 100 \%, 100 \%$ and $1.60 \%$ respectively with $98.40 \%$ diagnostic accuracy. Colposcopic diagnosis of invasive disease and histopathology report showed $100 \%$ correlation.

Conclusions: Correlation between RCI and histopathology was good. Predictive accuracy of colposcopy increased with increasing severity of disease.

Keywords: Carcinoma cervix, Cervical intraepithelial lesion (CIN), Reid's Combined Colposcopic Index (RCI)

\section{INTRODUCTION}

Cancer cervix occupies the top rank of gynaecological cancers in the developing countries. ${ }^{1}$ In India, it is the most common $(80 \%)$ cancer of all the genital tract malignancies and is one of the leading causes of cancer deaths amongst women. ${ }^{2}$ It is estimated that cervical cancer will occur in approximately 1 in 53 Indian women during their lifetime compared with 1 in 100 women in more developed regions of the world. ${ }^{3}$ Cervical cancer has a long latent period and can be prevented by simple treatment of cervical intraepithelial neoplasm, often on outpatient basis, it is important that screening programmes identify all women at risk while the disease is in its preinvasive stage. Colposcopy is one of the screening methods to detect preinvasive and invasive disease of the cervix with the goal to predict its histologic status. The specificity of colposcopy ranges between 10 
to $48 \%$ and sensitivity of $96 \% .^{4}$ The overall predictive accuracy of the Reid's Colposcopic Index is greater than $95 \% .^{5}$ Histopathology remains the gold standard for the diagnosis of the intra-epithelial and invasive cancers of the cervix. Based on the margins, colour, type of vascularity and iodine staining of the lesion, Reid and Scalzi proposed a four feature scoring system to designate the histologic diagnosis of the lesion and RCI was developed. ${ }^{6}$ The purpose of this study was to prospectively evaluate the RCI as a predictor of cervical intraepithelial lesion (CIN).

\section{METHODS}

After approval from the Institutional Academic Council, one hundred and twenty five adult married women attending gynae OPD in MDOH, Ludhiana with suspicious cervix were studied. Informed consent was taken from all the participants. On clinical examination, the criteria for inclusion were erosion, chronic cervicitis, healed lacerations, hypertrophied cervix, bleeding on touch, growth / ulcer on cervix and abnormal discharge from cervix. Women with frank carcinoma cervix, pregnancy, bleeding per vaginum at the time of examination, females who had used vaginal medications, vaginal contraceptives or douches in the last 48 hours of examination and post hysterectomy women were excluded from the study. After taking a detailed history and doing thorough clinical examination, colposcopy was done in all 125 women with suspicious cervix. Prior cervical cytology was done in all the participants in the study. RCI was used to score the colposcopic findings. ${ }^{6}$ Cervical biopsies were performed in colposcopically abnormal lesions and endocervical curettage (ECC) was done in unsatisfactory colposcopy.

\section{Technique of colposcopic examination}

In this study the colposcope used was Colpro 222 (proMIS Health care LLC, N.J., USA), a digital video colposcope. Counselling of women attending the OPD was done after taking detailed history which was noted in the colposcopy evaluation form. Women were put in the dorsal / lithotomy position and draped. Extended lithotomy position was used when cervix was pulled superiorly or was flushed with the vault. A bivalve self retaining vaginal speculum was used. Colposcopic examination was carried out as follows:

\section{The saline method}

The mucous was first swabbed off with cotton. ${ }^{7}$ The cervix and the vagina were thoroughly moistened with normal saline using a cotton swab. Gross lesions, vascular details and opacity of the epithelium were examined.

The green filter was then used to evaluate the vascular details (blood vessels appear dark black against a background of translucent epithelium) and enhanced contrast between normal and abnormal epithelium. This method should precede the application of the acetic acid.

\section{The classical or extended method}

After removing the excess of mucus with a dry or saline soaked cotton wool swab, the cervix was swabbed liberally with a large swab of loose cotton wool soaked in $3 \%$ acetic acid. ${ }^{8}$ All epithelium with a high nuclearcytoplasmic ratio turned white after acetic acid application. The vascular pattern was again evaluated under high magnification power (20X) using green filter.

The new squamo-columnar junction was identified and visualized. If the new squamo-columnar junction was not visualized on the ectocervix, it was looked for within the cervical canal.

\section{Iodine test}

An aqueous Lugol's iodine solution (50\%) was used to see the epithelium pattern which is dependent on the interaction between the cellular glycogen and the iodine.

Unsatisfactory colposcopy was declared if new squamocolumnar junction was not visualized in its entirety, if proper examination was not possible because of constant bleeding from the friable epithelium or cervix not visualized completely. In such cases colposcopic diagnosis could not be made.

Colposcopic findings were classified according to International Federation of Cervical Pathology and Colposcopy (I.F.C.P.C2003). ${ }^{9}$ Abnormal colposcopic findings were scored according to the RCI to help in predicting the underlying lesion and were scored in the categories of margin sharpness, epithelial color, vascular patterns and iodine staining. ${ }^{10}$

All the colposcopic signs except for iodine staining were scored after the application of copious amount of $3 \%$ acetic acid. Once an area of acetowhite change appeared the lesion was assessed and scored. Then lugol's iodine was applied and iodine staining reaction was recorded after assessment and scoring. Cervical biopsies were done under colposcopic guidance from abnormal areas. The site of biopsy in homogenous lesions was near the new squamocolumnar junction and in a heterogenous lesions, the most suspicious area was biopsied. The biopsy specimen was sent in $10 \%$ formalin solution for histopathological examination. In the paraffin block the sections were made perpendicular to the surface of the epithelium. ECC was performed in all the cases of unsatisfactory colposcopy. The aim was to sample the stroma and send it in $10 \%$ formalin solution for the examination.

All findings were recorded in a tabulated form and the results were expressed as percentages. Sensitivity, 
specificity and predictive values were calculated according to the formulas given below:

Table 1: Sensitivity, specificity and predictive values calculation.

\begin{tabular}{|lll|}
\hline \multicolumn{3}{|c|}{ Reference standard (gold standard) } \\
\hline Test Results & Disease present & Disease absent \\
\hline Positive & True positive $(a)$ & False positive $(b)$ \\
\hline Negative & True negative $(c)$ & False negative $(d)$ \\
\hline $\begin{array}{l}\text { Sensitivity }=\mathrm{a} /(\mathrm{a}+\mathrm{c}) ; \text { Specificity }=\mathrm{d} /(\mathrm{b}+\mathrm{d}) ; \text { Predictive } \\
\text { value }=\mathrm{a} /(\mathrm{a}+\mathrm{b}) ; \text { False positive rate }=\mathrm{b} /(\mathrm{a}+\mathrm{b}) ; \text { False } \\
\text { negative rate }=\mathrm{c} /(\mathrm{c}+\mathrm{d})\end{array}$ \\
\hline
\end{tabular}

\section{RESULTS}

This study was done on 125 adult married women with clinical diagnosis of suspicious cervix who came to the outpatient department of the hospital. All participants included in this study underwent pap smear examination followed by colposcopy. Colposcopic directed cervical biopsy was taken from the most suspicious area of the cervix in patients who had abnormal colposcopic findings. Authors observed that age of the participants ranged from 21 to 62 years and $42.40 \%$ of them were in 31- 40 years of age group. Maximum women (53.60\%) belonged to middle class, followed by $25.60 \%$ lower and $20.80 \%$ in upper class of socio economic status. Sikh and Hindu population with 61 women (48.80\%) each dominated the study followed by two Muslims (1.60\%) and one $(0.80 \%)$ Christian. Urban population was $63.20 \%$ as compared to the rural population which was $36.80 \%$. One hundred and one $(80.80 \%)$ women were pre menopausal and $24(19.20 \%)$ were post menopausal. Most of the women (44\%) had not used any contraceptive method. Barrier method was the commonest $(25.60 \%)$, followed by tubal ligation $(20.80 \%)$ and the least used contraceptive method was injection depoprovera (Table 2).
It was noted (Table 3) that forty one (32.80\%) participants had normal (Figure 1a) and 62 (49.60\%) abnormal colposcopic findings (Figure $1 \mathrm{~b}, \mathrm{c}, \mathrm{d}, \mathrm{e}, \mathrm{f}$ ).

Table 2: Socio demographic characteristics.

\begin{tabular}{|c|c|c|}
\hline & $\begin{array}{l}\text { No. of cases } \\
(n=125)\end{array}$ & $\%$ \\
\hline \multicolumn{3}{|l|}{ Age (years) } \\
\hline $21-30$ & 23 & 18.40 \\
\hline $31-40$ & 53 & 42.40 \\
\hline $41-50$ & 36 & 28.80 \\
\hline $51-60$ & 12 & 9.60 \\
\hline$>60$ & 1 & 0.80 \\
\hline \multicolumn{3}{|l|}{ Socio-economic status } \\
\hline Lower & 32 & 25.60 \\
\hline Middle & 67 & 53.60 \\
\hline Upper & 26 & 20.80 \\
\hline \multicolumn{3}{|l|}{ Religion } \\
\hline Hindu & 61 & 48.80 \\
\hline Sikh & 61 & 48.80 \\
\hline Muslim & 2 & 1.60 \\
\hline Christian & 1 & 0.80 \\
\hline \multicolumn{3}{|l|}{ Place of residence } \\
\hline Rural & 46 & 36.80 \\
\hline Urban & 79 & 63.20 \\
\hline \multicolumn{3}{|l|}{ Menstrual history } \\
\hline Pre menopausal & 101 & 80.80 \\
\hline Post menopausal & 24 & 19.20 \\
\hline \multicolumn{3}{|l|}{ Contraceptives used } \\
\hline Nil & 55 & 44.00 \\
\hline Barrier & 32 & 25.60 \\
\hline Tubal ligation (Tl) & 26 & 20.80 \\
\hline Copper T (Cut) & 8 & 6.40 \\
\hline Oral contraceptives (OC) & 3 & 2.40 \\
\hline $\begin{array}{l}\text { Injection depo provera } \\
\text { (IDP) }\end{array}$ & 1 & 0.80 \\
\hline
\end{tabular}

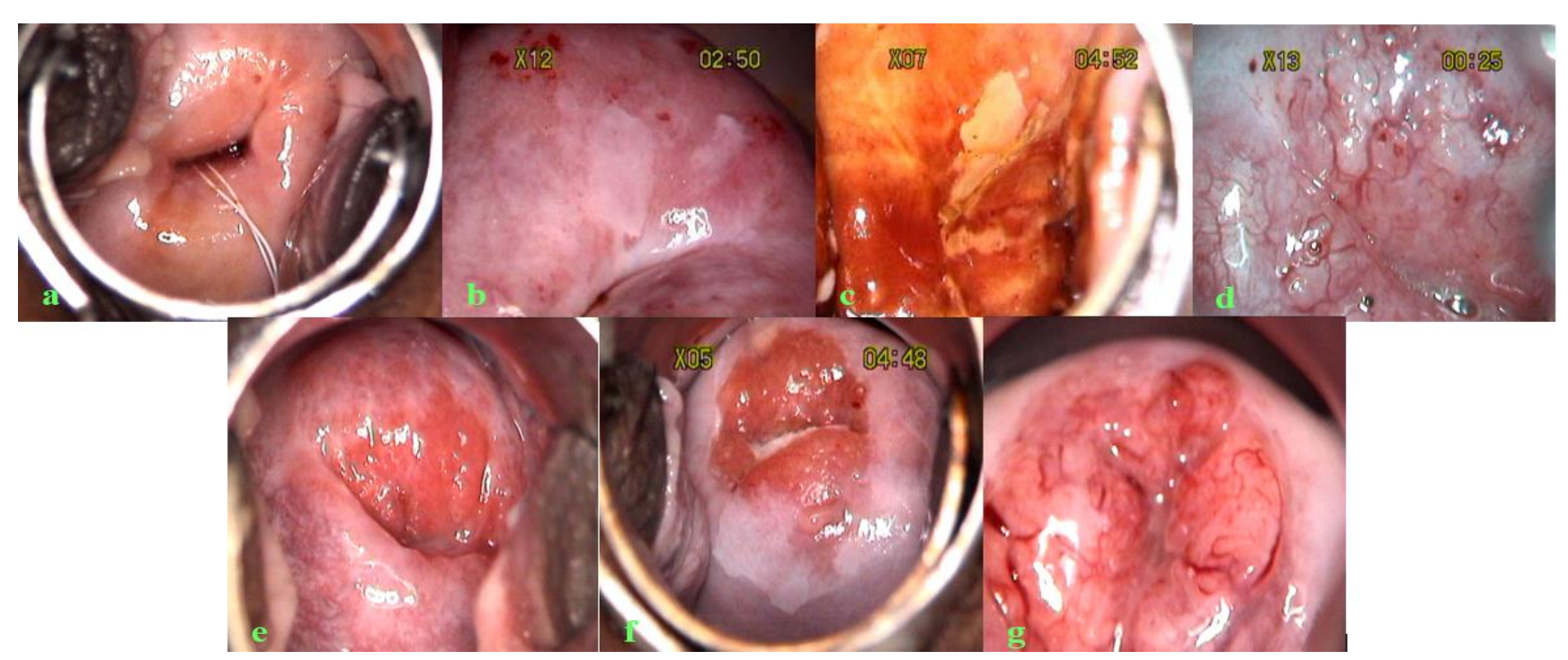

Figure 1: Colposcopic findings: (a) normal cervix; (b) acetowhite area; (c) negative iodine uptake; (d) mosaic and punctations; (e) CIN $1 \mathrm{HPV}$; (f) CIN 1/2; (g) suggestive of invasive disease. 
Six $(4.80 \%)$ of them had unsatisfactory colposcopy and in one $(0.80 \%)$, colposcopy was suggestive of invasive carcinoma (Figure 1g). Miscellaneous findings were observed in $12 \%$ of the cases. All women with suspicious colposcopic findings (Table 4) were scored according to Reid's colposcopic index.

Table 3: Distribution of subjects according to colposcopic classification.

\begin{tabular}{|lll|}
\hline Class & $\begin{array}{l}\text { No. of } \\
\text { cases } \\
(\mathrm{n}=125)\end{array}$ & $\%$ \\
\hline I Normal colposcopic finding & 41 & 32.80 \\
\hline II Abnormal colposcopic finding & 62 & 49.60 \\
\hline $\begin{array}{l}\text { III Suggestive of invasive } \\
\text { carcinoma }\end{array}$ & 1 & 0.80 \\
\hline IV Unsatisfactory colposcopy & 6 & 4.80 \\
\hline V Miscellaneous findings & 15 & 12.00 \\
\hline
\end{tabular}

Table 4: Distribution of subjects according to Reid's Colposcopic Index.

\begin{tabular}{|lll|}
\hline Reid's Colposcopic Index & $\begin{array}{l}\text { No. of cases } \\
(\mathbf{n}=62)\end{array}$ & $\%$ \\
\hline 0-2 Low grade disease & 47 & 37.60 \\
\hline 3-4 Intermediate grade disease & 11 & 8.80 \\
\hline 5-8 High grade disease & 4 & 3.20 \\
\hline
\end{tabular}

Forty seven $(37.60 \%)$ of them had low grade disease, 11 $(8.80 \%)$ intermediate and $4(3.20 \%)$ high grade disease. In one female, where colposcopy was suggestive of invasive carcinoma, colposcopy score was not given. In 6 participants, RCI could not be allotted due to unsatisfactory colposcopy.
Table 5: Distribution of subjects according to cervical biopsy report.

\begin{tabular}{|lll|}
\hline Cervical biopsy report & $\begin{array}{l}\text { No. of } \\
\text { cases } \\
(\mathbf{n = 6 9 )}\end{array}$ & $\%$ \\
\hline Chronic cervicitis & 40 & 57.97 \\
\hline Chronic cervicitis with sq metaplasia & 8 & 11.59 \\
\hline $\begin{array}{l}\text { Chronic cervicitis with endocervical } \\
\text { polyp }\end{array}$ & 5 & 7.24 \\
\hline Severe chronic cervicitis with erosion & 1 & 1.44 \\
\hline Epithelial hyperplasia with fibrosis & 1 & 1.44 \\
\hline CIN 1(HPV infection) & 2 & 2.88 \\
\hline CIN 1 & 9 & 13.04 \\
\hline CIN 2 / 3 & 1 & 1.44 \\
\hline Micro invasive sq cell ca & 1 & 1.44 \\
\hline Squamous cell carcinoma & 1 & 1.44 \\
\hline Total & 69 & \\
\hline
\end{tabular}

Table 6: Agreement between Reid's Colposcopic Index and histopathology.

\begin{tabular}{|ll|}
\hline $\begin{array}{l}\text { Reid's Colposcopic } \\
\text { Index }\end{array}$ & Histopathology \\
\hline $\begin{array}{l}\text { Low grade disease } \\
(\mathrm{n}=47)\end{array}$ & $\begin{array}{l}\text { CIN1 }(\mathrm{n}=4) \\
\text { CIN1(HPV) }(\mathrm{n}=2)\end{array}$ \\
$\begin{array}{l}\text { Colposcopic score } \\
\text { 0-2=HPV or CIN1 }\end{array}$ & $\begin{array}{l}\text { Ch cervicitis }(\mathrm{n}=34) \\
\text { Ch cervicitis with metaplasia }(\mathrm{n}=6)\end{array}$ \\
\hline $\begin{array}{l}\text { Intermediate grade } \\
\text { disease }(\mathrm{n}=11)\end{array}$ & CIN1 $(\mathrm{n}=4)$ \\
$\begin{array}{l}\text { Colposcopic score } \\
\text { 3-4=CIN1 or CIN2 }\end{array}$ & Ch cervicitis $(\mathrm{n}=5)$ \\
\hline $\begin{array}{l}\text { High grade disease } \\
(\mathrm{n}=4)\end{array}$ & Sq cell ca $(\mathrm{n}=1)$, CIN2/3 $(\mathrm{n}=1)$, \\
$\begin{array}{l}\text { Colposcopic score } \\
\text { 5-8 }=\text { CIN2 or CIN3 } 3\end{array}$ & CIN1 $(\mathrm{n}=1)$, Ch cervicitis $(\mathrm{n}=1)$ \\
\hline
\end{tabular}

Table 7: Abnormal colposcopic findings of 62 cases showing correlation with cervical biopsy.

\begin{tabular}{|c|c|c|c|c|c|c|c|}
\hline \multirow{2}{*}{ Biopsy } & & \multirow{2}{*}{$\mathbf{N}$} & \multicolumn{5}{|c|}{ Abnormal colposcopic findings } \\
\hline & & & AWA (\%) & PUN (\%) & $\operatorname{MOS}(\%)$ & $\operatorname{ATV}(\%)$ & NIU (\%) \\
\hline \multirow{5}{*}{$\begin{array}{l}\text { No CIN } \\
(49)\end{array}$} & chc & 36 & $22(61.11)$ & $17(47.22)$ & $3(8.33)$ & $1(2.78)$ & $1(2.78)$ \\
\hline & chc, sq met & 7 & $4(57.14)$ & $3(42.86)$ & - & - & $2(28.57)$ \\
\hline & chs, ecp & 4 & - & - & $1(25.00)$ & - & - \\
\hline & chc, ero & 1 & $1(100)$ & - & - & - & $1(100)$ \\
\hline & ehf & 1 & $1(100)$ & - & - & - & - \\
\hline \multicolumn{2}{|c|}{ CIN 1 (HPV) } & 2 & $2(100)$ & $1(50.00)$ & - & $1(50.00)$ & - \\
\hline \multicolumn{2}{|l|}{ CIN 1} & 9 & $9(100)$ & $2(22.22)$ & $2(22.22)$ & $1(11.11)$ & $4(44.44)$ \\
\hline \multicolumn{2}{|l|}{ CIN2/3 } & 1 & $1(100)$ & - & - & $1(100)$ & $1(100)$ \\
\hline \multicolumn{2}{|l|}{ sq c ca } & 1 & $1(100)$ & - & - & $1(100)$ & $1(100)$ \\
\hline
\end{tabular}

Figures in brackets represent abnormal colposcopic findings as percent of cervical biopsy. No Pt - number of patients chc - chronic cervicitis, sq met - squamous metaplasia, ecp - endocervical polyp, ero - erosion, ehf - epithelial hyperplasia with fibrosis, CIN - cervical intraepithelial neoplasm, HPV - human papilloma virus, sq c ca - squamous cell carcinoma, AWA - acetowhite area, MOS - mosaic, PUN - punctuations, ATV - atypical vessels, NIU - negative iodine uptake, N - number of cases.

All women with suspicious colposcopy findings $89.86 \%$ (62), with unsatisfactory colposcopy $8.70 \%$ (6) and one with the colposcopic findings suggestive of the presence of invasive carcinoma underwent cervical biopsy (Table 5). All women with unsatisfactory colposcopy also 
underwent ECC. Chronic cervicitis $57.97 \%$ (40) was the most common diagnosis. Low grade CIN was diagnosed on cervical biopsy in nine women and HPV related CIN in two, CIN2/3, micro invasive squamous carcinoma and non keratinizing poorly differentiated squamous cell carcinoma, one each was also confirmed on cervical biopsy. In six women with unsatisfactory colposcopy, no pre invasive or invasive pathology was detected on cervical biopsy and ECC was negative. Table 6 depicts agreement between Reid's Colposcopic Index and histopathology whereas Table 7 shows abnormal colposcopic findings of 62 cases and its correlation with cervical biopsy.

\section{DISCUSSION}

Cancer of the cervix is a preventable disorder as the different screening, diagnostic and therapeutic procedures are effective. One of the essential responsibilities of the gynaecologist is to detect neoplasm of the genital tract at the earliest. Colposcopy helps to distinguish between normal and abnormal cervical tissue.

In the present study all one hundred and twenty five married women with clinical diagnosis of suspicious cervix underwent colposcopy preceded by pap smear. Cervical biopsy was done in sixty nine women for abnormal colposcopic findings in 62 , invasive disease in one and unsatisfactory colposcopic findings in six. Grading of abnormal colposcopic findings was done using RCI to predict histological grade of the disease. In this study, maximum cases $(42.40 \%)$ belonged to age group of 31-40 years. Mean age at time of marriage was $20.04 \pm 3.26$ years and $12 \%$ of them conceived before the age of 18 years. Most common presenting complaint was discharge per vaginum $(54.40 \%)$, followed by pain abdomen $(45.60 \%)$ and post coital bleeding (16.80\%).

In present study abnormal colposcopic findings were seen in $62(49.6 \%)$ women which is similar as observed by Arora et al who also observed $51.87 \%$ abnormal colposcopy while evaluating 268 unhealthy cervices. ${ }^{11}$ The unsatisfactory colposcopic findings in present study (4.8\%) were comparable to Arora et al's observations $(3.73 \%)$. Present results are also in accordance with the findings of Navya et al who reported $54 \%$ benign, $18 \%$ CIN 1, $16 \%$ CIN 2 and 12\% as CIN 3 according to Reid colposcopic index. ${ }^{12} \mathrm{We}$ scored the abnormal colposcopic findings in 62 women according to the RCI and found the maximum number $(47,37.60 \%)$ of them with score 0 to 2 indicating low grade disease. Eleven women (8.88\%) showed intermediate grade disease and high grade disease with the score of 5 to 8 was found in $4(3.2 \%)$ cases.

In one participant, colposcopy was suggestive of the invasive disease. Maximum number of participants with abnormal colposcopic findings had chronic cervicitis (35.48\%) followed by hypertrophy $(17.4 \%)$ and erosion $(14.52 \%)$ on clinical examination. Colposcopy suggestive of invasive carcinoma in one female had polyp on examination. Colposcopic directed biopsy was done in 62 cases with abnormal colposcopic findings and 11 were proved to have CIN1/ CIN1 HPV. According to Dexeus et al, if biopsy is done in all patients with atypical colposcopic images, histological correlation in the form of dysplasia or malignancy is obtained in only about $10 \%$ of the cases. ${ }^{13}$ Authors found that one woman with high grade disease on colposcopy showed CIN2/3 on histology. One case with high grade disease on colposcopy was confirmed to have squamous cell carcinoma on colposcopically directed biopsy. One women showed colposcopy suggestive of invasive carcinoma and was proved to have microinvasive squamous cell carcinoma on biopsy. Diagnostic accuracy of colposcopy for invasive disease was $50.00 \%$. Six cases with unsatisfactory colposcopy showed chronic cervicitis on histopathology and endo cervical curettage was negative. Handa and Dhall studied 500 women with clinically suspicious cervix where they found that 96 had atypical colposcopic images and abnormal cytology in 7 cases. The histological confirmation for dysplasia or carcinoma was seen in 18 patients. They concluded that if colposcopy was done in all women on the basis of symptoms and clinical examination alone, the percentage of correlation decreased significantly. ${ }^{14}$

All the women with findings of suspicious colposcopy (62), unsatisfactory colposcopy (6) and colposcopy suggestive of invasive carcinoma (1) underwent cervical biopsy. Endocervical curettage was performed in all cases with unsatisfactory colposcopy. Chronic cervicitis $57.97 \%$ (40) was the most common diagnosis. Low grade CIN was diagnosed on cervical biopsy in nine cases and HPV related CIN1 in two, CIN 2/3 in one. Micro invasive squamous carcinoma and non keratinizing poorly differentiated squamous cell carcinoma; one each was also confirmed on cervical biopsy. In six women with unsatisfactory colposcopy, no pre invasive or invasive pathology was detected on cervical biopsy.

In women with no CIN on histopathology, the colposcopic examination showed correlation with acetowhite area in $58.00 \%$, with punctuations in $40.00 \%$, with mosaic in $8.00 \%$, with atypical vessels $4.00 \%$ and with negative iodine uptake in $10.00 \%$ of women. Correlation of $100 \%$ was seen between CIN1 HPV/ CIN1 on cervical biopsy with acetowhite area on colposcopic examination. Women with CIN1 HPV on histopathology showed $50.00 \%$ correlation with punctuations and atypical vessels on colposcopy. Women with CIN1 showed correlation of $22.22 \%$ each with punctuation and mosaic, $11.11 \%$ with atypical vessels and $44.44 \%$ with negative iodine uptake. One case with squamous cell carcinoma on histopathology showed acetowhite area, atypical vessels and negative iodine uptake. Women with CIN $2 / 3$ on histopathology showed $100 \%$ correlatation with acetowhite area, atypical vessels and negative iodine uptake. 
Authors observed that $12.77 \% \quad(n=6 / 47)$ showed agreement between RCI and histopathology for low grade disease, $36.36 \%(n=4 / 11)$ for intermediate disease and $75 \%(n=3 / 4)$ for high grade disease. For invasive disease correlation was $100 \%(n=1 / 1)$. Massad et al reported that only $37 \%$ of cases showed exact agreement between colposcopic impression using RCI and biopsy histology with poor strength of the correlation, however, sensitivity for RCI with a threshold of any lesion detected was $90 \% .{ }^{15}$ In present study, the overall predictive value (calculated as True positive / Total positive cases x $100 \%$ $=13 / 63 \times 100 \%$ ) and false positive rate (calculated as False positive/Total positive cases $\mathrm{x} 100 \%=50 / 63 \times 100 \%$ ) of clposcopy for preinvasive and invasive disease was $20.96 \%$ and $79.03 \%$ respectively in 63 cases in whom cervical biopsy was done.

In 6 women, colposcopy was unsatisfactory and so the colposcopic diagnosis could not be made. Diagnostic accuracy of colposcopy for invasive disease (calculated as True positive+True negative / Total cases of cervical biopsy $\times 100 \%=1+61 / 63 \times 100 \%$ ) was $98.41 \%$. In 63 cases, in whom cervical biopsy was done, the sensitivity, specificity, predictive value and false negative rate of colposcopy for invasive disease was 50\%, 100\%, 100\% and $1.61 \%$ respectively. Navya et al in 2016 reported a general accuracy of colposcopic findings using RCI for histopathology of cervical lesions was $92 \%$ and specificity $90.48 \% .^{12}$

Daron et al had observed sensitivity, specificity, positive and negative predictive values of a colposcopist's RCI score of $>3 / 6$ to detect CIN 3 or worse to be $37.3 \%(95 \%$ CI $32.5 \%-42.3 \%), 89.7 \%$ (88.6\%-90.8\%), 30.8\% (26.7\%$35.2 \%)$, and $92.1 \%(91.1 \%-93.0 \%)$, respectively and the three colposcopic signs were not individually sensitive in detecting CIN 3. ${ }^{16}$ In present study cervical histology of CIN2/3 or invasive disease depicted strong correlation $(100 \%)$ for colposcopic sign of negative iodine uptake, acetowhite area and atypical vessels.

High false positive rate of colposcopy for Low grade lesions in a study by Stafl and Mattingly was explained by the fact that colposcopic impressions were obscured by an epithelium with increased metabolic demand due to active metaplasia, inflammation or repair of CIN, which was characterised by punctuations and mosiaicsm that represented remodelling of vascular network. ${ }^{17}$ According to Edebiri atypical vessels on colposcopy may be present due to inflammatory processes. ${ }^{18}$

\section{CONCLUSION}

Predictive accuracy of colposcopy increased with increasing severity of disease. Doing colposcopy as a primary screening modality can be helpful in low recourse settings and developing countries where the patient compliance is poor. Using a scoring system like RCI can help us in studying the different changes in the cervix. We recommend colposcopic evaluation of suspicious cervix found on clinical examination and do the directed biopsy to reach the final diagnosis.

Funding: No funding sources

Conflict of interest: None declared

Ethical approval: The study was approved by the Institutional Academic Council

\section{REFERENCES}

1. Jemal A, Bray F, Center MM, Ferlay J, Ward E, Forman D. Global cancer statistics. CA Cancer J Clin. 2011;61(2):69-90.

2. Ferlay J, Shin HR, Bray F, Forman D, Mathers C, Perkin DM. GLOBOCAN 2008, Cancer Incidence and mortality worldwide: IARC cancer base No. 10 [internet]. Lyon, France: International Agency for Research on Cancer; 2010. Available at http//globocan.aarc.fr.

3. Institute for Health Metrics and Evaluation. The Challenge Ahead: Progress in Breast and Cervical Cancer. Institute of Health Metrics and Evaluation. 2011. Available at http://www.healthmetricsandevaluation.org/publicati ons/policyreport/challenge-ahead-progress-andsetbacksbreastand-cervical-cancer.

4. Miller AB. Cervical cancer screening programmes, managerial guidelines. WHO Geneva. 1992;6-14:448.

5. Dexeus S, Cararach M, Dexeus D. Role of colposcopy in modern Gynaecol Oncol. 2002;23(4):269-77.

6. Reid R, Stanhope CR, Herschman BR, Crum CP, Agronow SJ. Genital warts and cervical cancer. IV.A colposcopic index for differentiating subclinical papillomaviral infection from cervical intraepithelial neoplasia. Am J Obstet Gynecol. 1984;149(8):815-23.

7. Olstad P, Stafl A. Atlas of colposcopy. Oslo:Universities Forlaget;1972.

8. Burke L, Antonioli DA, Ducatman BS. Colposcopy text and atlas Norwalk; Appleton \& Lange;1991:727.

9. Walker P, De Palo G, Campion M, Barrasso R, Campion M, Girardi F, Jakob C, et al. International terminology of colposcopy: An update report from the International Fedration for Cervical Pathology and Colposcopy. Obstet Gynecol. 2003;101(1):1757 .

10. Mitchell DG. Reid,s Colposcopic Index in Colposcopic Assessment System. In: Barbara SA, Gregory L ed. Colposcopy principles and practice. An integrated text book and atlas. WB Saunders Co;2002:213-24.

11. Arora R, Vijaya K, Habeebullah S, Asha O. Colposcopic evaluation of unhealthy cervix. J Obstet Gynecol Ind. 2000;50:102-3.

12. Navya BN, Rashmi B, Ravikanth Go, Sathyavathi R Alva. Comparison of diagnostic accuracy of colposcopic findings using modified reid colposcopic 
index with histopathology in cervical lesions. JDMS. 2016;15:129-33.

13. Dexeus S Jr, Carrera JM, Coupez F. Colposcopy. W B Saunders Company, Philadelphia;1977;10:131-57.

14. Handa PR, Dhall GI. Colposcopy as diagnostic aid in cases of suspicious cervix. J Obstet Gynaecol. 1991;41(6):785-92.

15. Massad LS, Collins YC. Strength of correlations between colposcopic impression and biopsy histology. Gynecol Oncol. 2003;89:424-8.

16. Daron FG, Litaker MS. Prediction of cervical histologic results using an abbreviated Reid Colposcopic Index during ALTS. Am J Obstet Gynaecol. 2006;194(3):704-10.
17. Stafl A, Mattingly R. Angiogenesis of cervical neoplasia. Am J Obstet Gynecol. 1975;121(6):84552

18. Edbiri AA. The relative significance of colposcopic descriptive appearences in the diagnosis of cervical intraepithelial neoplasia. Int $\mathrm{J}$ Gynaecol Obstet. 1990;33(1):23-9.

Cite this article as: Verma I, Pundhir P, Kaur T, Jain V, Sood D. Evaluation of Reid's Combined Colposcopic Index as a predictor of cervical intraepithelial lesion. Int J Reprod Contracept Obstet Gynecol 2018;7:3724-30. 